\title{
Is iron deficiency modulating physical activity in COPD?
}

This article was published in the following Dove Medical Press journal:

International Journal of COPD

\author{
Clara Martín-Ontiyuelo' \\ Anna Rodó-Pin' \\ Antonio Sancho-Muñoz' \\ Juana María \\ Martinez-Llorens' \\ Mireia Admetlló' \\ Lluis Molina ${ }^{2}$ \\ Joaquim Gea' \\ Esther Barreiro' \\ Diego A Rodríguez \\ Chiaradía'
}

'Pulmonology Department, Hospital del Mar, Institut Hospital del Mar d'Investigacions Mèdiques (IMIM), Universitat Pompeu Fabra (UPF), CIBERES, (ISCiii), Barcelona, Spain; ${ }^{2}$ Cardiology Department, Hospital del Mar, Institut Hospital del Mar d'Investigacions Mèdiques (IMIM), Universitat Autónoma de Barcelona (UAB), Barcelona, Spain
Correspondence: Diego A Rodríguez Chiaradía

Pulmonology Department, Hospital del Mar, Institut Hospital del Mar d'Investigacions Mèdiques (IMIM), Universitat Pompeu Fabra (UPF), CIBERES, (ISCiii), Passeig Maritim 25, 08003 Barcelona, Spain

Tel +34932483548

$\mathrm{Fax}+34932483425$

Email darodriguez@psmar.cat

\begin{abstract}
There is evidence that iron plays a key role in the adequate functioning of skeletal muscle. While it has been demonstrated that nonanemic iron deficiency (NAID) affects exercise tolerance and response to exercise training in patients with COPD, the impact on daily physical activities (DPAs) remains unknown. Eighteen COPD patients with NAID (ferritin $<100 \mathrm{ng} / \mathrm{mL}$ or ferritin 100-299 $\mathrm{ng} / \mathrm{mL}$ with a transferrin saturation $<20 \%$ ) and 18 COPD patients without this abnormality, matched for age, gender, and the degree of airflow limitation (control group), were enrolled to the study. The primary outcome was the level of DPA assessed by accelerometers. Patients were (mean [SD]) 66 (7) years and were mostly male (70\%) and former smokers (52\%). Their forced expiratory volume at 1 second was 41 (16)\% predicted, carbon monoxide diffusing capacity was 47 (14)\% predicted and oxygen arterial pressure reached 70 (11) mmHg. DPA and the number of steps per day were lower in NAID COPD patients compared with controls (physical activity level 1.39 vs $1.59, P<0.05$; and 4,402 vs 6,975 steps/day, $P<0.05$, respectively). The percentage of patients with increased time spent sitting per day ( $>6$ hours) was higher in patients with NAID compared with controls $(73 \%$ vs $37 \%, P<0.05)$. In addition, the percentage of patients doing moderate to vigorous physical activity per day $(>3$ metabolic equivalents of task, at least 30 minutes) was lower in this group $(66 \%$ vs $100 \%, P<0.05)$. The presence of iron deficiency was associated with reduced DPA in COPD patients. Further studies are needed to evaluate iron reposition and their impact on the level of physical activity in these patients.
\end{abstract}

Keywords: COPD, comorbidities, physical activity, iron, nutrition, chronic disease

\section{Introduction}

Nonanemic iron deficiency (NAID) in the adult population remains an important public health problem worldwide. ${ }^{1}$ Moreover, NAID prevalence in chronic complex disease is very high, rising up to $40 \%$ in patients with $\mathrm{COPD}^{2}$ and $50 \%$ in patients with chronic heart failure. ${ }^{3}$ Particularly, COPD patients with NAID showed more dyspnea, ${ }^{4}$ higher values of pulmonary arterial pressure at rest, ${ }^{5}$ and lower exercise capacity with a reduced training-induced response than patients without iron deficiency. ${ }^{2}$ These functional alterations cannot be fully explained by hemodynamic deterioration. An impairment in oxygen utilization by the peripheral muscles may also account for the reported loss of muscle function and/or exercise tolerance in COPD. ${ }^{6}$ This factor can be especially relevant for those diseases in which the peripheral muscle involvement has an impact on daily physical activity (DPA). ${ }^{7}$ In line with this, the effects of reduced physical activity and disuse in COPD have been extensively investigated in several studies ${ }^{8,9}$ resulting in a vicious circle with reductions in DPA leading to deconditioning and a further deterioration of skeletal muscle function. Despite the clinical relevance and research problem, to the best of our knowledge, no studies have examined so far the impact of NAID on DPA in patients with COPD. In this context, we sought to compare 
the level of DPA in COPD patients with NAID and in those COPD patients with an adequate iron status.

To address this question, we conducted a pilot study, in which 18 patients with $\mathrm{COPD}^{10}$ and NAID (hemoglobin $>12 \mathrm{~g} / \mathrm{dL}$ in females and $>13 \mathrm{~g} / \mathrm{dL}$ in males, ferritin $<100 \mathrm{ng} / \mathrm{mL}$ or ferritin 100-299 $\mathrm{ng} / \mathrm{mL}$ with a transferrin saturation $<20 \%)^{2}$ were recruited along with 18 COPD patients with normal iron content. The latter patients were age-matched and were controlled for disease severity (control group). DPA was measured using the SenseWear Pro Armband (BodyMedia, Pittsburgh, PA, USA), an accelerometer already validated in patients with COPD. ${ }^{11}$ DPA was measured for 7 consecutive days. The minute-by-minute output of the number of steps and metabolic equivalents of task (METs) was exported for further analysis using a SenseWear Professional version. The variables chosen for this analysis were the following: 1) total daily number of steps; 2) moderate physical activity, defined as any activity $\geq 3$ METs; 3 ) physical activity level (PAL); ${ }^{12}$ and 4) time spent sitting per day. ${ }^{13}$ Lung function (Easy One, Switzerland; Jaeger Master Screen Body; CareFusion; Germany) was measured according to European Respiratory Society/American Thorax Society standards. ${ }^{14}$ The results were expressed as predicted normal values. ${ }^{15}$ The study was approved by the local research ethics committee (CEImParc de Salut MAR) and complies with the Declaration of Helsinki. Informed written consent was obtained from all patients before enrollment.

Results are presented as percentages or mean (SDs), unless otherwise stated. Parametric (Student's $t$-test) and nonparametric tests (Wilcoxon test) were performed to assess the statistical significance of differences between groups. Pearson or Spearman correlation coefficient $(r)$ was used to correlate DPA with hematologic variables (hemoglobin, transferrin saturation, and ferritin). A $P$-value $\leq 0.05$ was considered significant. All analyses were performed using the IBM SPSS Statistics for Windows, Version 20.0 (IBM Corp., Armonk, NY, USA).

The characteristics of the study population are indicated in Table 1. As expected, the baseline clinical and functional variables of patients with COPD and NAID were not different from control COPD patients. Compared with control patients, NAID patients showed lower levels of the parameter steps per day and PAL. Also, the percentage of patients with adequate daily levels of moderate physical activity ( $>30$ minutes) was significantly lower in NAID COPD patients than in the control COPD patients. Conversely, the percentage of patients with prolonged time spent sitting ( $\geq 6$ hours/day) was significantly greater in NAID group (Table 1). No significant correlations were observed between hematologic variables and physical activity among all COPD patients.

To the best of our knowledge, the current study is the first to explore the impact of NAID on physical activity in patients with COPD. Previously, some of us published original research on the negative effects of NAID on exercise capacity and the response to pulmonary rehabilitation, ${ }^{2}$ indicating a potential therapeutic target to improve exercise tolerance. However, it is widely known that the relationship between physical activity and exercise capacity in COPD is weak ${ }^{16}$ because of their specific determinants. ${ }^{9}$ Although the assessment of exercise capacity is a key point in the evaluation of pharmacological and nonpharmacological interventions, physical activity allows to monitor these effects on daily-life activities of these patients. ${ }^{17}$ In this context, muscle dysfunction is one of the main mechanisms involved in the low physical activity with a prognosis implication in these patients. ${ }^{8}$ It is clear that muscle dysfunction contributes to both exercise intolerance and low physical activity, ${ }^{7}$ with pulmonary rehabilitation being the only treatment widely accepted. However, other specific interventions have already been implemented in clinical settings in the last years. ${ }^{7-18}$ Recently, there has been great interest in the effect of iron deficiency on skeletal muscle as a potential contributor to muscle dysfunction in COPD and other chronic complex diseases. ${ }^{19}$ Despite that our results do not fully support this hypothesis; we can speculate that iron deficiency in the skeletal muscle could be a likely cause of muscle dysfunction that generates low physical activity and exercise intolerance. Therefore, over the last year, we have carried out a randomized control trial to explore the effects of iron reposition in COPD patients (EudraCT 2016-001238-89). Participants are currently being recruited for the trial. As of June 1, 2018, a total of 30 patients with NAID and COPD have been recruited into the trial. Data collection is anticipated to be completed by the end of 2019 .

Our current study has some limitations that should be considered when interpreting the results. First, the sample size was small and included only patients with moderate and severe COPD; these findings may not be applicable to the wider population of patients with COPD. In contrast, the adequate matched groups by airflow limitation, carbon monoxide diffusing capacity, or comorbidities may not occur in more conventional studies.

In conclusion, NAID in moderate to severe COPD patients could be a potential modulator of physical activity. Research is needed to examine the physiological 
Table I Clinical and functional characteristics of COPD patients with and without nonanemic iron deficiency (NAID)

\begin{tabular}{|c|c|c|c|}
\hline Clinical and functional variables & All patients $(\mathrm{N}=36)$ & NAID COPD (N=|8) & $\begin{array}{l}\text { Non-NAID COPD } \\
\text { controls }(\mathbf{N}=18)\end{array}$ \\
\hline \multicolumn{4}{|l|}{ Clinical characteristics } \\
\hline $\begin{array}{l}\text { Male/female, } \mathrm{n} \\
\text { Age, years } \\
\text { Current smokers, } \mathrm{n}(\%) \\
\text { Body mass index, } \mathrm{kg} / \mathrm{m}^{2} \\
\text { Fat-free mass index, } \mathrm{kg} / \mathrm{m}^{2} \\
\text { CAT score } \\
\text { AECOPD } \geq 2 / \text { year, } \mathrm{n}(\%) \\
\text { Charlson index }\left[\text { median }\left(\mathrm{P}_{5-95}\right)\right]\end{array}$ & $\begin{array}{l}21 / 15 \\
66(7) \\
19(52) \\
24(4) \\
16(2) \\
16(8) \\
10(27) \\
2(2.1-2.6)\end{array}$ & $\begin{array}{l}10 / 8 \\
67(6) \\
9(50) \\
24(3) \\
15(1) \\
17(9) \\
5(27) \\
2(2.1-2.6) \\
\end{array}$ & $\begin{array}{l}11 / 7 \\
64(7) \\
10(55) \\
25(4) \\
16(1) \\
15(7) \\
5(27) \\
2(2.2-2.5)\end{array}$ \\
\hline \multicolumn{4}{|l|}{ Treatment, $\mathrm{n}$} \\
\hline $\begin{array}{l}\text { LABD } \\
\text { ICS } \\
\text { Beta-blockers } \\
\text { Aspirin } \\
\text { Statins }\end{array}$ & $\begin{array}{l}36 \\
8 \\
3 \\
3 \\
4\end{array}$ & $\begin{array}{l}18 \\
4 \\
1 \\
1 \\
2\end{array}$ & $\begin{array}{l}18 \\
4 \\
2 \\
2 \\
2\end{array}$ \\
\hline \multicolumn{4}{|l|}{ Pulmonary function } \\
\hline $\begin{array}{l}\mathrm{FEV}_{1} / \mathrm{FVC}, \% \\
\mathrm{FEV}_{1}, \% \text { predicted } \\
\mathrm{DLco}^{2} \% \text { predicted } \\
\mathrm{PaO}_{2}, \mathrm{mmHg} \\
\mathrm{PaCO}_{2}, \mathrm{mmHg} \\
\mathrm{IC} / \mathrm{TLC}\end{array}$ & $\begin{array}{l}43(12) \\
41(16) \\
47(14) \\
70(11) \\
42(6) \\
0.28(0.09)\end{array}$ & $\begin{array}{l}44(13) \\
40(16) \\
46(14) \\
67(11) \\
42(5) \\
0.28(0.08)\end{array}$ & $\begin{array}{l}43(12) \\
42(22) \\
49(15) \\
72(10) \\
42(6) \\
0.29(0.11)\end{array}$ \\
\hline QMVC, kg & $37(13)$ & $35(\mathrm{II})$ & $40(15)$ \\
\hline \multicolumn{4}{|l|}{ Hematological characteristics } \\
\hline $\begin{array}{l}\text { Hemoglobin, } g / d L \\
\text { MCV (fL) } \\
\text { MCHC (g/dL) } \\
\text { Transferrin saturation, \% } \\
\text { Ferritin, } \mathrm{ng} / \mathrm{mL}\end{array}$ & & $\begin{array}{l}14.5(1) \\
90(5) \\
32(1) \\
20(5) \\
70(27)\end{array}$ & $\begin{array}{l}15.2(1) \\
92(4) \\
33(1) \\
40(3)^{*} \\
235(39)^{*}\end{array}$ \\
\hline C-reactive protein, $\mathrm{mg} / \mathrm{dL}$ & & $0.6(I)$ & $0.7(0.9)$ \\
\hline \multicolumn{4}{|l|}{ Daily physical activity } \\
\hline $\begin{array}{l}\text { Steps per day } \\
\text { Physical activity level } \\
\text { Moderate physical activity, min/day } \\
\text { Moderate activity per day, \% of patients } \\
\text { Time spent sitting, min/day } \\
\text { Prolonged time spent sitting, \% of patients }\end{array}$ & $\begin{array}{l}5,726(3,337) \\
1.49(0.2) \\
103(80) \\
83 \\
397(196) \\
55\end{array}$ & $\begin{array}{l}4,402(2,145) \\
1.39(0.1) \\
85(80) \\
66 \\
448(184) \\
73\end{array}$ & $\begin{array}{l}6,975(3,8 \mid 3)^{* * *} \\
1.59(0.2)^{* * *} \\
120(78) \\
100^{\dagger} \\
342(201) \\
37^{+\dagger}\end{array}$ \\
\hline
\end{tabular}

Notes: Data are presented as mean (SD) unless otherwise stated. Moderate physical activity per day: at least 30 minutes; prolonged time spent sitting per day: $>6$ hours. $* P<0.001 ; * * P=0.020 ; * * * P=0.019 ;{ }^{\dagger} P=0.010 ;{ }^{\dagger} P=0.048$.

Abbreviations: AECOPD, acute exacerbation of chronic obstructive pulmonary disease; CAT, chronic obstructive pulmonary disease assessment test; DLco, carbon monoxide diffusing capacity; $\mathrm{FEV}_{\mathrm{I}} / \mathrm{FVC}$, forced expiratory volume at I second/forced vital capacity; ICS, inhaled corticosteroid; IC/TLC, inspiratory capacity/total lung capacity; LABD, long-acting bronchodilators; MCV, mean corpuscular volume; $\mathrm{MCHC}$, mean corpuscular hemoglobin concentration; $\mathrm{PaCO}$, carbon dioxide arterial pressure; $\mathrm{PaO}_{2}$, oxygen arterial pressure; QMVC, quadriceps maximal strength during maximum voluntary contraction.

mechanisms implicated and the potential role of therapeutic interventions.

\section{Acknowledgments}

The authors would like to thank Ana Balañá, Concepción Ballano, and Laura Gutiérrez for their assistance in collecting the data for this study. They want to acknowledge the support of the Instituto de Salud Carlos-III (FIS 14/00713 [FEDER], FIS 18/00075 [FEDER], FIS 17/00649 [FEDER], and BA 17/00025), CIBERES (ESF02/2017), Spanish Respiratory
Society (SEPAR) 2016 and 2017 (409/2017), Catalan Foundation of Pulmonology (FUCAP) 2016 and 2017, Catalan Respiratory Society (SOCAP) 2017, Ministerio de Economía y Competitividad (SAF2014-54371 [FEDER]), Menarini (2015-2018), and Vifor Pharma (2017-2018).

The abstract of this paper was presented at the 2017 European Respiratory Society Congress as a poster presentation. The poster's abstract was published in "Poster Abstracts" in European Respiratory Journal 2017:50: PA3457: DOI: 10.1183/1393003.congress-2017.PA3457. 


\section{Disclosure}

The authors report no conflicts of interest in this work.

\section{References}

1. McLean E, Cogswell M, Egli I, Wojdyla D, de Benoist B. Worldwide prevalence of anaemia, WHO Vitamin and Mineral Nutrition Information System, 1993-2005. Public Health Nutr. 2009;12(4):444-454.

2. Barberan-Garcia A, Rodríguez DA, Blanco I, et al. Non-anaemic iron deficiency impairs response to pulmonary rehabilitation in COPD. Respirology. 2015;20(7):1089-1095.

3. Klip IT, Comin-Colet J, Voors AA, et al. Iron deficiency in chronic heart failure: an international pooled analysis. Am Heart J. 2013;165(4):575-582.

4. Silverberg DS, Mor R, Weu MT, Schwartz D, Schwartz IF, Chernin G. Anemia and iron deficiency in COPD patients: prevalence and the effects of correction of the anemia with erythropoiesis stimulating agents and intravenous iron. BMC Pulm Med. 2014;14(1):24.

5. Plesner LL, Schoos MM, Dalsgaard M, et al. Iron deficiency in COPD associates with increased pulmonary artery pressure estimated by echocardiography. Heart Lung Circ. 2017;26(1):101-104.

6. Ruiter G, Manders E, Happé CM, et al. Intravenous iron therapy in patients with idiopathic pulmonary arterial hypertension and iron deficiency. Pulm Circ. 2015;5(3):466-472.

7. Maltais F, Decramer M, Casaburi R, et al. An official American Thoracic Society/European Respiratory Society statement: update on limb muscle dysfunction in chronic obstructive pulmonary disease. $A m J$ Respir Crit Care Med. 2014;189(9):e15-e62.

8. Barreiro E. Skeletal muscle dysfunction in COPD: novelties in the last decade. Arch Bronconeumol. 2017;53(2):43-44.

9. Garcia-Aymerich J, Félez MA, Escarrabill J, et al. Physical activity and its determinants in severe chronic obstructive pulmonary disease. Med Sci Sports Exerc. 2004;36(10):1667-1673.
10. Vogelmeier CF, Criner GJ, Martínez FJ, et al. Global strategy for the diagnosis, management, and prevention of chronic obstructive lung disease 2017 report: GOLD executive summary. Arch Bronconeumol. 2017;53(3):128-149.

11. Haskell WL, Lee IM, Pate RR, et al. Physical activity and public health: updated recommendation for adults from the American College of Sports Medicine and the American Heart Association. Med Sci Sports Exerc. 2007;39(8):1423-1434.

12. World Health Organization. Global Recommendations on Physical Activity for Health. Geneva, Switzerland: WHO; 2010:2-60.

13. Patel AV, Maliniak ML, Rees-Punia E, Matthews CE, Gapstur SM. Prolonged leisure time spent sitting in relation to cause-specific mortality in a large US cohort. Am J Epidemiol. 2018;187(10): 2151-2158.

14. Pellegrino R, Viegi G, Brusasco V. Interpretative strategies for lung function tests. Eur Respir J. 2005;26(5):948-968.

15. García-Río F, Calle M, Burgos F, et al. Spanish society of pulmonology and thoracic surgery (SEPAR). Arch Bronconeumol. 2013;49(9): 388-401.

16. Watz H, Pitta F, Rochester CL, et al. An official European Respiratory Society statement on physical activity in COPD. Eur Respir J. 2014; 44(6): 1521-1537.

17. Demeyer H, Burtin C, Hornikx M, et al. The minimal important difference in physical activity in patients with COPD. PLoS One. 2016;11(4): e0154587.

18. Jaitovich A, Barreiro E. Skeletal muscle dysfunction in chronic obstructive pulmonary disease. What we know and can do for our patients. Am J Respir Crit Care Med. 2018;198(2):175-186.

19. Stugiewicz M, Tkaczyszyn M, Kasztura M, Banasiak W, Ponikowski P, Jankowska EA. The influence of iron deficiency on the functioning of skeletal muscles: experimental evidence and clinical implications. Eur J Heart Fail. 2016;18(7):762-773.
International Journal of COPD

\section{Publish your work in this journal}

The International Journal of COPD is an international, peer-reviewed journal of therapeutics and pharmacology focusing on concise rapid reporting of clinical studies and reviews in COPD. Special focus is given to the pathophysiological processes underlying the disease, intervention programs, patient focused education, and self management protocols.

\section{Dovepress}

This journal is indexed on PubMed Central, MedLine and CAS. The manuscript management system is completely online and includes a very quick and fair peer-review system, which is all easy to use. Visit http://www.dovepress.com/testimonials.php to read real quotes from published authors. 